\title{
Is hypoxic pulmonary vasoconstriction important during single lung ventilation in the
lateral decubitus lung ventilation in position?
}

Hypoxic pulmonary vasoconstriction (HPV) has not been demonstrated in human single lung anaesthesia in the lateral decubitus position (LDP). The purpose of this study was to determine whether (1) HPV occurs in the non-dependent, nonventilated lung, and (2) if the infusion of sodium nitroprusside (SNP) inhibits HPV. During intravenous anaesthesia the tracheas of seven patients were intubated with double lumen endotracheal tubes. Standard monitors plus radial and pulmonary arterial catheters were placed. Patients were positioned in the LDP and haemodynamic and gas exchange data were recorded for each of three stages; I: two-lung ventilation, II: single, dependent lung ventilation (ILV) and III: $I L V$ with infusion of $S N P$. In stage II the $\mathrm{PaO}_{2}$ decreased from $531 \pm 42 \mathrm{~mm} \mathrm{Hg}$ to $285 \pm 42 \mathrm{mmHg}(P<0.05)$ and $\dot{Q} s / \dot{Q} t$ increased from $12.3 \pm 2.7$ to $29.0 \pm 6.3 \%(P<0.05)$. With SNP infusion there was a $30 \%$ increase in cardiac index $(C I)(P<0.05)$. The SNP infusion was not associated with changes in $\dot{Q} s / \dot{Q} t$

\section{Key words}

ANAESTHESIA: thoracic;

LUNG: perfusion, pulmonary artery;

OXYGEN: hypoxia;

POSITION: effects, ventilation, cardiovascular.

Received from the Departments of Anaesthesia* and Thoracic Surgery†, The Toronto Hospital, Toronto, Canada and the Department of Anesthesiology, University of California, San Diego, CAt.

Presented in part at the Annual Meeting of the Canadian Anaesthetists Society, Quebec City, Quebec, Canada, June 1991 and at the International Anesthesia Research Society 66th Congress, San Francisco, CA, March, 1992.

Address correspondence to: Dr. A.N. Sandler, Department of Anaesthesia, Toronto General Division, The Toronto Hospital, 200 Elizabeth Street, GW 2-502, Toronto, Ontario, M5G 2 C4.

Accepted for publication 28th September, 1993.

\author{
Mark Friedlander MB ChB FRCPC,* \\ Alan Sandler MSc MB ChB FRCPC, ${ }^{*}$ \\ Brian Kavanagh MB BCh BSc MRCP(I), ${ }^{*}$ \\ Timothy Winton MD FRCPC, $\uparrow$ \\ Jonathan Benumof MD $\ddagger$
}

or $\mathrm{PaO}_{2}$. This model demonstrates changes in $\dot{Q}_{s} / \dot{Q}_{t}$ and $\mathrm{PaO}_{2}$ associated with single-lung ventilation in ASA I and II patients in the LDP but we were unable to demonstrate inhibition of HPV by SNP.

En position de décubitus latéral (PDL), l'existence de vasoconstriction hypoxique (VHP) au niveau du poumon isolé n'a pas été démontrée. Cette étude vise à déterminer 1) si la VHP se manifeste au poumon supérieur non ventilé et 2) si une perfusion de nitroprussiate de sodium (SNP) inhibe la VHP. Au cours d'une anesthésie intraveineuse, sept patients sont intubés avec un tube à double lumière. Le monitorage habituel est complété d'une canule artérielle et d'un cathéter de SwannGanz. Les patients sont placés en PDL et les paramètres hémodynamiques et les échanges gazeux mesurés pour chacun des trois stades de l'étude; stade I: ventilation bipulmonaire; stade II: ventilation unipulmonaire du poumon inférieur (VIP); et stade III: VIP avec perfusion de SNP. Au stade II, la $\mathrm{PaO}_{2}$ s'abaisse de $531 \pm 42 \mathrm{mmHg}$ à $285 \pm 42 \mathrm{mmHg}(P<0,05)$ et le $\dot{Q}_{s} / \dot{Q} t$ augmente de $12,3 \pm 2,7$ à 29,0 $\pm 6,3 \%(P<$ $0,05)$. Pendant la perfusion de SNP, lindex cardiaque augmente de $30 \%(P<0,05)$. La perfusion de $S N P$ ne provoque pas de changements de $\dot{Q} s / \dot{Q} t$, ni de $\mathrm{PaO}_{2}$. Ce modèle montre que des changements de $\dot{Q} s / \dot{Q}_{t}$ et de $\mathrm{PaO}_{2}$ se manifestent pendant la ventilation unipulmonaire chez des patients $A S A$ I et II en PDL mais ne montre pas que le SNP inhibe la VHP.

Thoracic surgery may be greatly facilitated by separation and differential ventilation of each lung. ${ }^{1}$ Ventilation and anaesthetic vapours may then be delivered to one or both lungs and collapse of either can be carried out. ${ }^{2}$ During single lung ventilation the potential exists for considerable intrapulmonary shunting of deoxygenated pulmonary arterial blood resulting in arterial hypoxaemia. Hypoxic pulmonary vasoconstriction (HPV), as a mechanism of pulmonary auto-regulation, is thought to attenuate this development of hypoxaemia by actively reducing the per- 
fusion of deoxygenated blood through non-ventilated lung tissue. ${ }^{2}$ However, there are no studies which have examined the administration of potent vasodilator drugs to humans in the lateral position whose nondependent lung is not ventilated during one-lung ventilation of the dependent lung.

The aim of this study was to determine: (1) if the autoregulatory phenomenon of HPV can be implicated and/or demonstrated in the human pulmonary circulation of the non-dependent, non-ventilated lung, and if (2) the infusion of the vasodilator sodium nitroprusside (SNP) would inhibit this autoregulation.

\section{Methods}

\section{Demographics}

Ten patients were included in the study. Three were withdrawn before data were collected due to (1) technical difficulties with the double lumen tube, (2) haemodynamic instability after induction of anaesthesia, and (3) excessive delay in reaching stable gas exchange conditions.

Data were obtained from seven patients (three male, four female) of mean age $62 \pm 2$ (SEM) yr and mean weight $65.7 \pm 6.6 \mathrm{~kg}$. Patients included were ASA class I or II and scheduled for elective thoracotomy where onelung ventilation was indicated. Patients with cardiovascular disease or with contraindications to the use of SNP or pulmonary artery catheterisation were excluded.

\section{Anaesthesia and monitoring}

Patients received premedication (morphine, glycopyrrolate) at the discretion of the attending anaesthetist and were brought to the operating room two hours before scheduled surgery. A $16 \mathrm{~g}$ peripheral $i v$ infusion was started and a radial artery cannulated. After preoxygenation, patients were anaesthetized with thiopentone (1-3 $\left.\mathrm{mg} \cdot \mathrm{kg}^{-1}\right)$, fentanyl $\left(5-10 \mathrm{mg} \cdot \mathrm{kg}^{-1}\right)$, pancuronium $\left(0.1 \mathrm{mg} \cdot \mathrm{kg}^{-1}\right)$, midazolam $\left(0.1 \mathrm{mg} \cdot \mathrm{kg}^{-1}\right)$ and the trachea and left main bronchus were intubated with a left double-lumen endotracheal tube of appropriate size (Rusch AG, Waiblingen, West Germany). Correct endotracheal and endobronchial placement was confirmed with fibreoptic bronchoscopy. A pulmonary artery catheter (PAC) was inserted via a right internal jugular catheter and the patient was positioned in the lateral position for surgery. Bronchoscopy was used to confirm correct double-lumen tube position and a chest radiograph was taken to demonstrate the position of the PAC. Additional midazolam and fentanyl were administered $i v$ as needed during induction and maintenance of anaesthesia. Ringer's lactate and/or vasopressors (ephedrine, neosynephrine) were given to maintain near normal blood pressure, heart rate and preload.
TABLE I Experimental sequence

\begin{tabular}{llll}
\hline Stage & $I$ & $I I$ & $I I I$ \\
\hline Lungs* & 2 & 1 & 1 \\
Position & Lateral & Lateral & Lateral \\
SNP & Off & Off & On \\
Anaesthesia & $\dot{N}$ & $\dot{N}$ & $\dot{N}$ \\
\hline
\end{tabular}

${ }^{*}$ Lungs $=$ number of lungs ventilated.

$i v=$ intravenous.

\section{Measurement}

PULMONARY ARTERY CATHETER

A pulmonary artery catheter was placed as described above and used to measure pulmonary artery occlusion pressure (PAOP), cardiac index (CI) by thermodilution, mean pulmonary artery pressure (PAP), mixed venous oxygen partial pressure $\left(\mathrm{P}_{\bar{v}} \mathrm{O}_{2}\right)$ and to calculate pulmonary and systemic vascular resistance (PVR and SVR) and pulmonary shunt ( $\dot{\mathrm{Q} s} / \dot{\mathrm{Q}} \mathrm{t})$.

\section{BLOOD SAMPLING}

All arterial blood gas $(\mathrm{ABG})$ samples were analyzed in the operating room laboratory (Reg Radiometer, Copenhagen, Denmark) within five minutes of sampling and the results returned within ten minutes of sampling. During each experimental stage an arterial blood sample was collected for laboratory measurement of haemoglobin concentration.

\section{Experimental sequence (Table I)}

After ten minutes of two-lung ventilation in the lateral position stable gas exchange was confirmed by two consecutive $A B G$ samples five minutes apart. At this stage (I) the first set of standard haemodynamic and gas exchange data were recorded (see Table II). Ventilation to the non-dependent lung was then discontinued and the lung was allowed to collapse. After at least ten minutes stable gas exchange was confirmed by two consecutive ABG samples with $\mathrm{PaO}_{2}$ within $30 \mathrm{mmHg}$ of each other, and the standard haemodynamic and gas exchange data were recorded for stage II (Table II). Infusion of SNP was started at $3 \mathrm{mg} \cdot \mathrm{kg}^{-1} \cdot \mathrm{min}^{-1}$ and adjusted to decrease the mean systemic blood pressure by $25 \%$. When the mean arterial pressure (MAP) was stable and stable gas exchange confirmed by consecutive ABG sampling, the standard haemodynamic and gas exchange data were recorded for stage III (Table II). At the end of stage III, SNP was discontinued, the study was terminated, and two-lung ventilation resumed. Surgery was then undertaken with anaesthetic agents at the discretion of the attending anaesthetist. 
TABLE II Standard haemodynamic and gas exchange data (SHGED)

\section{Haemodynamic}

Heart rate

Mean arterial blood pressure

Mean pulmonary artery pressure

Pulmonary artery pressure

Pulmonary artery occlusive pressure

Central venous pressure

Cardiac output

Systemic vascular resistance

Pulmonary vascular resistance

\section{Ventilation/gas exchange}

Tidal volume

Peak inspiratory pressure

Total lung compliance

Respiratory rate

Inspired $\mathrm{FIO}_{2}$

Arterial blood gases

$\mathrm{SaO}_{2}, \mathrm{~Sv}_{2}, \mathrm{PvO}_{2}$

Qs/Qt

\section{Statistical analysis}

Data are expressed as mean \pm SEM. Statistical analysis included one-way repeated measures ANOVA followed by post-hoc Scheffe F-tests, or one-tailed paired Student's t tests. Statistical significance was inferred where $P<$ 0.05. Statistical procedures were performed using Apple MacIntosh Statview II statistical programme.

\section{Results}

The patients' age, weight, anaesthetic drug dosage and intravenous fluid requirements are shown in Table III. Results of haemodynamic and gas exchange measurements are shown in Table IV. During Stage I (two-lung ventilation in the lateral position) mean haemodynamic values for the seven patients were: MAP and MPAP 81 $\pm 3 \mathrm{mmHg}$ and $20 \pm 2 \mathrm{mmHg}$ respectively. The mean PAOP pressure was $13 \pm 2 \mathrm{mmHg}$ and $\mathrm{CI} 2.4 \pm 0.4$. Mean $\mathrm{PaO}_{2}$ was $531 \pm 42 \mathrm{mmHg}$ and mean shunt (Q்) Qt) was $12.3 \pm 2.7 \%$. On instituting one-lung ventilation by discontinuing ventilation to the non-dependent lung (Stage II) there were no changes in MAP, MPAP, PAOP, CI, SVR or PVR. The $\mathrm{PaO}_{2}$ decreased (by $246 \mathrm{mmHg}$ ) and the Qs/Qt increased (by 16.7\%) $(P<0.05)$. With infusion of SNP (Stage III) there was a $30 \%$ increase in CI from $2.5 \pm 0.4$ to $3.2 \pm 0.5$ and a decrease in SVR $(P<0.01)$.

\section{Discussion}

With two-lung ventilation in the lateral decubitus position (LDP) the haemodynamic and gas exchange data were within the expected range. With one-lung ventilation $\mathrm{PaO}_{2}$ decreased, the $\dot{\mathrm{Q}} / \dot{\mathrm{Q}} \mathrm{t}$ increased and the $\mathrm{CI}$ re-
TABLE III Demographic data (mean \pm SEM)

\begin{tabular}{lc}
\hline Age (yr) & $62 \pm 2$ \\
Weight $(\mathrm{kg})$ & $65.7 \pm 6.6$ \\
Height $(\mathrm{cm})$ & $165 \pm 6$ \\
Midazolam $(\mathrm{mg})$ & $5.3 \pm 0.4$ \\
Fentanyl $(\mathrm{mg})$ & $820 \pm 90$ \\
Thiopentone $(\mathrm{mg})$ & $250 \pm 40$ \\
Pancuronium $(\mathrm{mg})$ & $11 \pm 1$ \\
SNP $\left(\mathrm{mg} \cdot \mathrm{kg}^{-1} \cdot \mathrm{min}^{-1}\right)$ & $3.6 \pm 0.5$ \\
$i$ fluids $(\mathrm{ml})$ & $960 \pm 180$ \\
\hline
\end{tabular}

TABLE IV Results (mean \pm SEM)

\begin{tabular}{|c|c|c|c|}
\hline & $\begin{array}{l}I \\
\text { Baseline (2LV) }\end{array}$ & $\begin{array}{l}\text { II } \\
\text { Pre.SNP(ILV) }\end{array}$ & $\begin{array}{l}I I I \\
\text { SNP (ILV) }\end{array}$ \\
\hline $\mathrm{MAP}(\mathrm{mmHg})$ & $81 \pm 3$ & $86 \pm 4$ & $65 \pm 3$ \\
\hline MPAP $(\mathrm{mmHg})$ & $20 \pm 2$ & $20 \pm 3$ & $17 \pm 2$ \\
\hline PAOP (mmHg) & $13 \pm 2$ & $11 \pm 2$ & $9 \pm 2$ \\
\hline $\mathrm{CI}$ & $2.4 \pm 0.4$ & $2.5 \pm 0.4$ & $3.2 \pm 0.5 \dagger$ \\
\hline $\begin{array}{l}\text { SVR } \\
\text { dynes } \cdot \sec ^{-1} \cdot \mathrm{cm}^{-5} \\
\text { PVR }\end{array}$ & $1584 \pm 355$ & $1601 \pm 280$ & $931 \pm 178 \dagger$ \\
\hline dynes $\sec ^{-1} \cdot \mathrm{cm}^{-5}$ & $160 \pm 35$ & $166 \pm 23$ & $131 \pm 22$ \\
\hline $\mathrm{PaO}_{2}(\mathrm{mmHg})$ & $531 \pm 42$ & $285 \pm 42^{*}$ & $225 \pm 47^{*}$ \\
\hline $\mathrm{PvO}_{2}(\mathrm{mmHg})$ & $57 \pm 6$ & $52 \pm 4$ & $51 \pm 3$ \\
\hline $\mathrm{S}_{\bar{v}} \overline{\mathrm{O}} \mathrm{O}_{2}(\%)$ & $86 \pm 2$ & $82 \pm 2$ & $83 \pm 0$ \\
\hline Qs/Qt (\%) & $12.3 \pm 2.7$ & $29.0 \pm 6.3^{*}$ & $32.8 \pm 4.5^{*}$ \\
\hline
\end{tabular}

$* P<0.05$ II:I, III:I

$\dagger P<0.05$ III:II.

Baseline $=$ 2-lung ventilation, no sodium nitroprusside (SNP); PreSNP = 1-lung ventilation, no SNP; SNP = 1-lung ventilation, SNP; MAP $=$ mean arterial pressure; MPAP $=$ man pulmonary arterial pressure; $\mathrm{PAOP}=$ pulmonary artery occlusion pressure; $\mathrm{CI}=$ cardiac index; SVR = systemic vascular resistance; $P V R=$ pulmonary vascular resistance; $\mathrm{PaO}_{2}=$ partial pressure arterial oxygen; $\mathrm{PvO}_{2}=$ partial pressure pulmonary venous oxygen; $\mathrm{S}_{\overline{\mathrm{O}}} \mathrm{O}_{2}(\%)=$ mixed venous hemoglobin saturation.

mained unchanged. With infusion of SNP the CI increased by $30 \%$. Before offering an interpretation of our findings, consideration should be given to possible limitations in the experimental methods. First, the dose and rate of SNP was strictly limited to depress MAP by approximately $25 \%$. This dose may have been insufficient to have an appreciable effect on the pulmonary shunt and $\mathrm{PaO}_{2}$. Secondly, a larger sample size may have resulted in statistical significance in Stage III but it was not possible to extend the study for logistical reasons. In this study all patients were placed on the appropriate side for the subsequent thoracotomy. Therefore, we did not control for lung side differences as patients were either on their left $(n=5)$ or right $(n=2)$ sides. There was no mechanical effect on lung parenchyma as the data were collected before chest opening. Although we noted the side in which the pulmonary artery catheter tip was 
sited radiologically, we do not believe that the measurement is affected by the side as long as the catheter tip is not in a Zone I position.

When any part of a lung is collapsed, not ventilated, or ventilated with an hypoxic gas mixture the pulmonary vessels in that area respond by increasing resistance to flow. This has been shown to be due to pulmonary vasoconstriction and has been demonstrated in numerous animal and human studies. ${ }^{3-17}$ This intrinsic reflex vasoconstriction of vessels perfusing hypoxic alveoli diverts blood flow from non-ventilated to ventilated lung units. ${ }^{18}$ The presence of this reflex hypoxic pulmonary vasoconstriction has been calculated to attenuate the arterial hypoxaemia which one would expect from a right to left shunt through a large hypoxic compartment. ${ }^{19}$ It is thus protective by decreasing the right to left shunt created by the non-ventilated area, as in canine one-lung anaesthesia. ${ }^{20}$ The presence and importance of HPV has never, to our knowledge, been clearly demonstrated in one-lung anaesthesia in humans in the lateral position.

The effect of positive-pressure ventilation on pulmonary perfusion in the anaesthetized, paralyzed patient in the lateral decubitus position on lung perfusion has been studied. Perfusion is relatively greater in the dependent lung mainly due to gravity. ${ }^{21}$ The average lung blood flow distribution is $40 \%$ in the nondependent lung and $60 \%$ in the dependent lung. ${ }^{2}$ During one-lung ventilation of the dependent lung only, gravity causes a vertical gradient in the distribution of blood flow in favour of the dependent lung. In addition surgical retraction and lung compression cause a further diversion of blood flow. However, the most important reduction in blood flow to the non-dependent lung has been shown, in animals, to be caused by active hypoxic pulmonary vasoconstriction. ${ }^{21}$ The role of HPV in reducing pulmonary blood flow in humans is not clear.

Drugs with vasoactive properties can inhibit HPV $22-40$ but the clinical importance of this inhibition with hypotensive agents like SNP have not been clearly demonstrated. Similar experimental models in dogs have demonstrated HPV with single-lung ventilation or hypoxic ventilation. Sodium nitroprusside has been used in these models to induce pulmonary vasodilatation and hypoxaemia, presumably by ablation of HPV. ${ }^{22}$ In these models, increased pulmonary vascular resistance was produced by intravenous infusion of oleic acid (which caused a miliary embolic effect); ${ }^{36}$ hypoxic two-lung ventilation; ${ }^{37}$ or atelectasis, ${ }^{38}$ or unilateral hypoxia. ${ }^{39}$ Intravenous infusions of SNP and nitroglycerine in these models decreased $\mathrm{PaO}_{2}$ and increased $\mathrm{Q} s / \mathrm{Q} t$. This led the authors to conclude that HPV was active in these models and ablated by SNP. Benumof ${ }^{22}$ suggested that these models are physiologically similar to human pulmonary disease and single-lung ventilation and suggested that
HPV and its ablation by SNP might be demonstrated in a human experiment similar to one performed by Bjertnas et al. using halothane. ${ }^{40}$

The $\mathrm{PaO}_{2}$ decrease and increase in shunt with onelung ventilation suggests that active HPV is occurring because, without active redistribution of pulmonary perfusion, one would expect shunts in the range of $35-45 \%$ due to gravitational effects, with resultant hypoxaemia (35\% is the lower limit because that would be the shunt with the left lung in the non-dependent position). ${ }^{2}$ However, with SNP infusion the changes in $\mathrm{PaO}_{2}$ and $\mathrm{Q}$ s! Q $t$ did not reach statistical significance.

The clinical implications of our findings are that a useful HPV response occurs in patients undergoing one-lung ventilation in the lateral decubitus position and that the anaesthetist should be aware of, and avoid, factors known to decresae HPV. We were surprised that SNP did not increase $\dot{Q} / \dot{Q} t$ during single-lung ventilation. This raises the question of the importance of HPV in this clinical situation. It is possible that with larger numbers the trends observed in $\dot{\mathrm{Q}} \mathrm{s} / \mathrm{Q} \mathrm{t}$ and $\mathrm{PaO}_{2}$ may have, reached statistical significance, allowing estimation of changes in HPV. However, no differences were observed in $\mathrm{Qs} / \mathrm{Qt}$ or $\mathrm{PaO}_{2}$ with infusion of SNP. Even if the trends had reached statistical significance the magnitude of the changes would be small.

\section{References}

1 Benumof $J L$. One lung ventilation and hypoxic pulmonary vasoconstriction: Implications for anaesthetic management. Anesth Analg 1985; 64: 821-33.

2 Benumof $J L$. Anesthesia for Thoracic Surgery. New York: W.B. Saunders, 1987.

3 von Euler US, Liljestrand G. Observations on the pulmonary arterial blood pressure in the cat. Acta Physiol Scand 1946; 12: 301-20.

4 Motley HL, Cournand A, Werko L, Himmelstein A, Dresdale $D$. The influence of short periods of induced anoxia upon pulmonary artery pressures in man. Am J Physiol 1947; 150: 315-20.

5 Reeves JT, Wagner WW Jr., McMurtry IF, Grover RF. Physiological effects of high altitude on the pulmonary circulation. International Review of Physiology 1979; 20: 289-310.

6 Konietzko N, Matthys H. Kardiopulmonale Adaptation an akute Hypoxia. Klinische Wochenschrift 1976; 54: 1116-7.

7 Fuchs KI, Moore LG, Rounds S. Pulmonary vascular reactivity is blunted in pregnant rats. J Appl Physiol 1983; 53: 703-7.

8 Campbell AGM, Dawes GS, Fishman AP, Hyman AI. Pulmonary vasoconstriction and changes in heart rate during asphyxia in immature foetal lambs. $J$ Physiol (Lond) 1966; 192: 93-110.

9 Cohn HE, Sacke EJ, Heymann MA, Rudolph AM. 
Cardiovascular responses to hypoxemia and acidemia in unanesthetized fetal lambs. Am J Obstet Gynecol 1972; 120: 817-24.

10 Stahlman $M$, Shepard F, Gray $J$, Young $W$. The effects of hypoxia and hypercapnia on the circulation in newborn lambs. J Pediatr 1964; 65: 1091-2.

11 Lewis AB, Heymann MA, Rudolph AM. Gestational changes in pulmonary vascular responses in fetal lambs in utero. Circ Res 1976; 39: 536-41.

12 Benumof JL, Wahrenbrock EA. Blunted hypoxic pulmonary vasoconstriction by increased lung vascular pressures. J Appl Physiol 1975; 38: 846-50.

13 Scanlon TS 3rd, Benumof JL, Wahrenbrock EA, Nelson $W L$. Hypoxic pulmonary vasoconstriction and the ratio of hypoxic lung to perfused normoxic lung. Anesthesiology 1978; 49: 177-81.

14 Marshall BE, Marshall C, Benumof JL, Saidman LJ. Hypoxic pulmonary vasoconstriction in dogs: effects of lung segment size and oxygen tension. J Appl Physiol 1981; 51: 1543-51.

15 Carlson AJ, Bindslev L, Santesson J, Gottlieb I, Hedenstierna $G$. Hypoxic pulmonary vasoconstriction in the human lung: the effect of prolonged unilateral hypoxic challenge during anaesthesia. Acta Anaesthesiol Scand 1985; 29: 346-51.

16 Tucker A, Reeves JT. Nonsustained pulmonary vasoconstriction during acute hypoxia in anesthetized dogs. Am J Physiol 1975; 228: 756-61.

17 Malik AB, Kidd BSL. Time course of pulmonary vascular response to hypoxia in dogs. Am J Physiol 1973; 224: 1-6.

18 Voelkel NF. Mechanisms of hypoxic pulmonary vasoconstriction. Am Rev Respir Dis 1986; 133: 1186-95.

19 Marshall $B E$, Marshall $C$. Continuity of response to hypoxic pulmonary vasoconstriction. J Appl Physiol 1980; 59: 189-96.

20 Thomas HM 3rd, Garrett RC. Strength of hypoxic vasoconstriction determines shunt fraction in dogs with atelectasis. J Appl Physiol 1982; 53: 44-51.

21 Benumof $J L$. One-lung ventilation and hypoxic pulmoanry vasoconstriction: implications for anesthetic management. Anesth Analg 1985; 64: 821-33

22 Benumof $J L$. Hypoxic pulmonary vasoconstriction and infusion of sodium nitroprusside (Editorial). Anesthesiology 1979; 50: 481-3.

23 Bishop MJ, Cheney FW. Minoxidil and nifedipine inhibit hypoxic pulmonary vasoconstriction. J Cardiovasc Pharmacol 1985; 5: 184-9.

24 Simonneau G, Escourrou P, Duroux P, Lockhart A. Inhibition of hypoxic pulmonary vasoconstriction by nifedipine. N.Engl J Med 1981; 304: 1582-5.

25 Redding GJ, Tuck $R$, Escourrou $P$. Nifedipine attenuates hypoxic pulmonary vasoconstriction in awake piglets. Am Rev Respir Dis 1984; 129: 785-9.
26 McMurtry IF, Davidson AB, Reeves JT, Grover RF. Inhibition of hypoxic pulmonary vasoconstriction by calcium antagonists in isolated rat lungs. Circ Res 1976; 38 : 99-104.

27 Furman WR, Summer WR, Kennedy TP, Sylvester JT. Comparison of the effects of dobutamine, dopamine, and isoproterenol on hypoxic pulmonary vasoconstriction in the pig. Crit Care Med. 1982; 10: 371-4.

28 Johansen I, Benumof JL. Reduction of hypoxia-induced pulmonary artery hypertension by vasodilator drugs. Am Rev Respir Dis 1979; 199: 375.

29 Conover WB, Benumof JL, Key TC. Ritodrine inhibition of hypoxic pulmonary vasoconstriction. Am J Obstet Gyn 1983; 146: 652-6.

30 Marin JLB, Orchard C, Chakrabarti $M K$, Sykes $M K$. Depression of hypoxic pulmonary vasoconstriction in the dog by dopamine and isoprenaline. Br J Anaesth 1979; 51: 303-12.

31 Sykes MK, Loh L, Seed RF, Kafer ER, Chakrabarti $M K$. The effect of inhalational anaesthetics on hypoxic pulmonary vasoconstriction and pulmonary vascular resistance in the perfused lungs of the dog and cat. $\mathrm{Br} \mathrm{J}$ Anaesth 1972; 44: 776-88.

32 Sykes $M K$, Davies DM, Chakrabarti MK, Loh $L$. The effects of halothane, trichlorethylene and ether on the hypoxic pressor response and pulmonary vascular resistance in the isolated, perfused cat lung. $\mathrm{Br} \mathrm{J}$ Anaesth 1973; 45: 655-63.

33 Benumof $J L$, Wahrenbrock EA. Local effects of anesthetics on regional hypoxic pulmonary vasoconstriction. Anesthesiology 1975; 43: 525-32.

34 Mathers J, Benumof $J L$, Wahrenbrock EA. General anesthetics and regional hypoxic pulmonary vasoconstriction. Anesthesiology 1977; 46: 111-4.

35 Marshall $C$, Lindgren $L$, Marshall $B E$. Effects of halothane, enflurane, and isofurane on hypoxic pulmonary vasoconstriction in rat lungs in vitro. Anesthesiology 1984; 60: 304-8.

36 Colley PS, Cheney FW Jr., Hlastala MP. Ventilationperfusion and gas exchange effects of nitroprusside in dogs with normal and edematous lungs. Anesthesiology 1979; 50: 489-95.

37 Hill $A B$, Sykes $M K$, Reyes $A$. A hypoxic pulmonary vasoconstrictor response in dogs during and after infusion of sodium nitroprusside. Anesthesiology 1979; 50: 484-8.

38 Colley PS, Cheney FW. Sodium nitroprusside increases $\dot{\mathrm{Q}} \mathrm{s} / \dot{\mathrm{Q}} \mathrm{t}$ in dogs with regional atelectasis. Anesthesiology 1977; 47: 338-41.

39 D'Oliveira $M$, Sykes $M K$, Chakrabarti $M K$, Orchard C. Keslin J. Depression of hypoxic pulmonary vasoconstriction by sodium nitroprusside and nitroglycerine. $\mathrm{Br} \mathrm{J}$ Anaesth. 1981; 53: 11-8.

40 Bjertnas $L J$, Hauge $A$, Nakken $K F$, Bredesen JE. Hypoxic pulmonary vasoconstriction: inhibition due to anesthesia. Acta Physiol Scand 1976; 96: 283-5. 